\title{
INTERFACIAL ELECTRONIC CHARGE TRANSFER AND DENSITY OF STATES IN SHORT PERIOD Cu/Cr MULTILAYERS (U)
}

A.F. Bello

T. Van Buuren

J.E. Klepeis

T.W. Barbee, Jr.

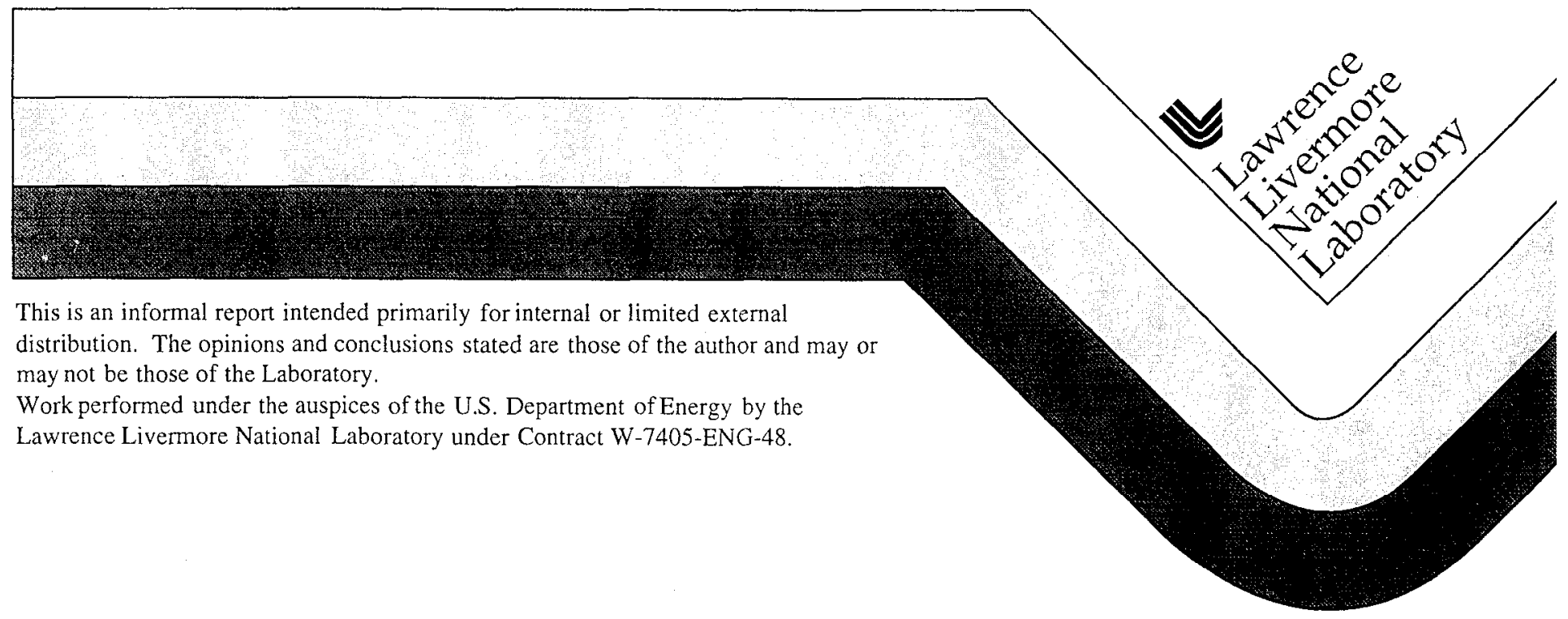




\section{DISCLAIMER}

This document was prepared as an account of work sponsored by an agency of the United States Government. Neither the United States Government nor the University of California nor any of their employees, makes any warranty, express or implied, or assumes any legal liability or responsibility for the accuracy, completeness, or usefulness of any information, apparatus, product, or process disclosed, or represents that its use would not infringe privately owned rights. Reference herein to any specific commercial product, process, or service by trade name, trademark, manufacturer, or otherwise, does not necessarily constitute or imply its endorsement, recommendation, or favoring by the United States Government or the University of California. The views and opinions of authors expressed herein do not necessarily state or reflect those of the United States Government or the University of California, and shall not be used for advertising or product endorsement purposes.

This report has been reproduced directly from the best available copy.

Available to DOE and DOE contractors from the Office of Scientific and Technical Information

P.O. Box 62, Oak Ridge, TN 37831

Prices available from (615) 576-8401, FTS 626-8401

Available to the public from the

National Technical Information Service

U.S. Department of Commerce

5285 Port Royal Rd.,

Springfield, VA 22161 


\title{
INTERFACIAL ELECTRONIC CHARGE TRANSFER AND DENSITY OF STATES IN SHORT PERIOD Cu/Cr MULTILAYERS
}

\author{
A. F. Bello, T. Van Buuren, J. E. Klepeis, T. W. Barbee, Jr. \\ Lawrence Livermore National Laboratory, Livermore, CA 94551.
}

\section{INTRODUCTION AND BACKGROUND}

Nanometer period metallic multilayers are ideal structures to investigate electronic phenomena at interfaces between metal films since interfacial atoms comprise a large atomic fraction of the samples. The $\mathrm{Cu} / \mathrm{Cr}$ binary pair is especially suited to study the interfaces in metals since these elements are mutually insoluble, thus eliminating mixing effects and compound formation and the lattice mismatch is very small. This allows the fabrication of high structural quality $\mathrm{Cu} / \mathrm{Cr}$ multilayers that have a structure which can be approximated in calculations based on idealized atomic arrangements. The electronic structure of the $\mathrm{Cu}$ and the $\mathrm{Cr}$ laycrs in several samples of thin $\mathrm{Cu} / \mathrm{Cr}$ multilayers were studied using $\mathrm{x}$-ray absorption spectroscopy (XAS). Total electron yield was measured and used to study the white lines at the $\mathrm{Cu}_{2}$ and $\mathrm{L}_{3}$ absorption edges. The white lines at the $\mathrm{Cu}$ absorption edges are strongly related to the unoccupied $\mathrm{d}$ orbitals and are used to calculate the amount of charge transfer between the $\mathrm{Cr}$ and $\mathrm{Cu}$ atoms in interfaces. Analysis of the $\mathrm{Cu}$ white lines show a charge transfer of 0.026 electrons/interfacial $\mathrm{Cu}$ atom to the interfacial $\mathrm{Cr}$ atoms. In the Cu XAS spectra we also observe a van Hove singularity between the $L_{2}$ and $L_{3}$ absorption edges as expected from the structural analysis. The absorption spectra are compared to partial density of states obtained from a full-potential linear muffin-tin orbital calculation. The calculations support the presence of charge transfer and indicate that it is localized to the first two interfacial layers in both $\mathrm{Cu}$ and $\mathrm{Cr}$.

\section{EXPERIMENT}

All the $\mathrm{Cu} / \mathrm{Cr}$ multilayer films studied were fabricated by $\mathrm{DC}$ magnetron sputtering. Base pressures were typically $10^{-7}$ torr; argon sputter gas at a pressure of about $2 \times 10^{-4}$ torr was used. In these samples all layers were designed to have an integer number of monolayers (ML), where the thickness of a monolayer was calculated using bulk structures (FCC and BCC). Expected growth directions ([111]-Cu and [110]-Cr) of the constituent elements were also assumed. Table I presents the samples prepared for this study and their structural characteristics.

Table I. Cu/Cr Bilayers of Varying Periods

\begin{tabular}{|c|c|c|c|}
\hline $\begin{array}{c}\text { Bilayer Thickness } \\
\text { of Cu/Cr [ML] }\end{array}$ & $\begin{array}{c}\text { Bilayer Thickness } \\
\text { of Cu/Cr }[\AA]\end{array}$ & $\begin{array}{c}\text { Bilayer Period } \\
{[\AA]}\end{array}$ & $\begin{array}{c}\% \text { Cu in } \\
\text { bilayer }\end{array}$ \\
\hline $3 / 6$ & $6.25 / 12.89$ & 19.14 & 32.6 \\
\hline $6 / 8$ & $12.53 / 16.31$ & 28.84 & 43.4 \\
\hline $3 / 3$ & $6.25 / 6.44$ & 12.69 & 49.2 \\
\hline $6 / 6$ & $12.53 / 12.89$ & 25.42 & 49.3 \\
\hline $8 / 8$ & $16.66 / 16.31$ & 32.97 & 50.5 \\
\hline $5 / 5$ & $10.43 / 10.19$ & 20.63 & 50.57 \\
\hline $8 / 6$ & $16.66 / 12.89$ & 29.55 & 56.4 \\
\hline $6 / 3$ & $12.53 / 6.44$ & 18.97 & 66.1 \\
\hline & & $\mathrm{Cu}(111)$ & 100 \\
\hline
\end{tabular}

Table I. Set of $\mathrm{Cu} / \mathrm{Cr}$ samples studied. The samples were designed with the layer thicknesses shown and fabricated using independently measured $\mathrm{Cu}$ and $\mathrm{Cr}$ deposition rates.

Total Electron Yield (TEY) $x$-ray absorption experiments were conducted at Beamline 8-2 of the Stanford Synchrotron Radiation Laboratory (SSRL). Data was acquired after annealing the sample at progressively higher temperatures in order to remove oxygen contamination from the sample surface. $\Lambda \mathrm{n}$ optical pyrometer monitored the annealing temperature which was kept below $600 \mathrm{C}$. Details of the experiment setup are presented in another paper ${ }^{1}$.

\section{RESULTS AND DISCUSSION}


A major complicating factor in $\mathrm{x}$-ray absorption is oxide contamination, which occurs when samples are in ambient atmosphere. Here, scans were taken after progressively higher temperature anneals to determine just when the oxide signals ${ }^{4}$ disappeared. For $\mathrm{Cu}_{5} / \mathrm{Cr}_{5}$, the data taken at $300 \mathrm{C}$ and higher temperature anneals removed the oxide signatures. At $300 \mathrm{C}$, features not directly related to the oxide were preserved. Higher temperature anneals distorted these features. Figure 1 shows how the $\mathrm{Cu}$ spectrum evolves upon annealing, starting with a slight shoulder due to the $\mathrm{CuO}$ and a relatively large absorption peak due to the $\mathrm{Cu}_{2} \mathrm{O}$. There is also one broad peak between the $\mathrm{L}_{3}$ and $\mathrm{L}_{2}$ absorption edges, indicative of a $\mathrm{BCC}$ symmetry point, where the DOS increases (van Hove singularity). The spectrum change is continued by the disappearance of the shoulder and a slight decrease in intensity of the absorption peak at about 300 C. Higher temperatures show the spectrum gradually becoming more like that for annealed $\mathrm{Cu}_{5} / \mathrm{Cu}_{5}$ or bulk $\mathrm{Cu}$, and at the final annealing temperature of $500 \mathrm{C}$, the spectrum clearly shows the three peaks in the $\mathrm{L}_{3}$ edge that is the distinct signature for $\Gamma \mathrm{CC} \mathrm{Cu}$.

On the DOS calculations, two methods were used. ${ }^{5}$ The first is the full-potential linear muffin-tin orbital (FP) method ${ }^{16.7}$, which employs a localized basis that provides a convenient framework for projecting out individual atom- and angular momentum-resolved partial densities of states (DOS). The partial DOS were calculated using a Mulliken decomposition as described by Hoffman ${ }^{8}$ and $\mathrm{McMahan}^{9}$. The FP method makes no shape approximation to the crystal potential, whereas methods based on the atomic sphere approximation (ASA) assume that the potential is spherically symmetric about each atom. The second method, although less accurate, is the atomic sphere approximation, linear muffin-tin potential method, which works reasonably well for close-packed systems and provides an alternate means of obtaining the partial DOS. Therefore, ASA calculations were carried out to cross-check the FP results. The ASA method is the one used by Ebert, et. al. ${ }^{10}$ in their study of $L_{2,3} \mathrm{X}$-ray absorption of Cu multilayers.

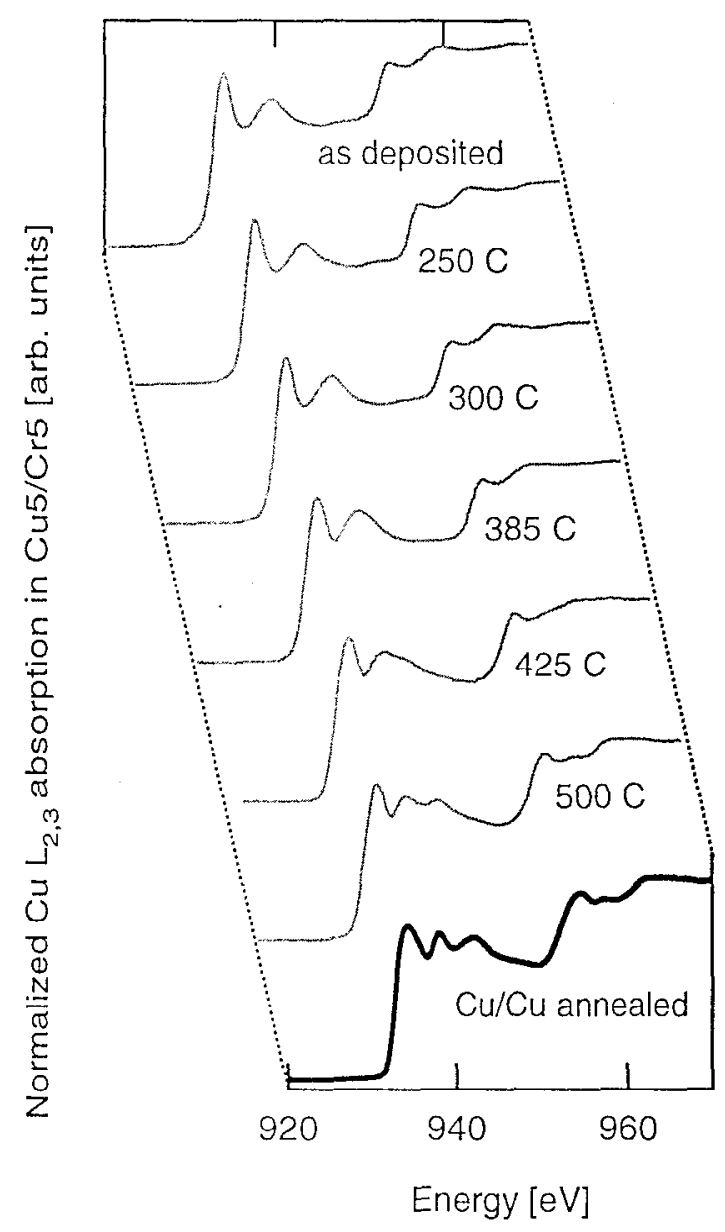

Figurc 1. Cu spectra from $\mathrm{Cu}_{5} / \mathrm{Cr}_{5}$ as it is annealed progressively to higher temperatures. For clarity, the axes are shifted for each spectrum. For comparison, the annealed $\mathrm{Cu}_{5} / \mathrm{Cr}_{5}$ is shown at the bottom.

Integrating the DOS up to the Fermi energy gives 11 electrons, but integrating just the d-band DOS gives 9.89 electrons instead of the 10 electrons normally associated with the full $\mathrm{d}$-band of $\mathrm{Cu}$. This 
amount of unoccupied d-states make is possible to observe the white lines in the near-edge $\mathrm{x}$-ray absorption of $\mathrm{Cu}$.

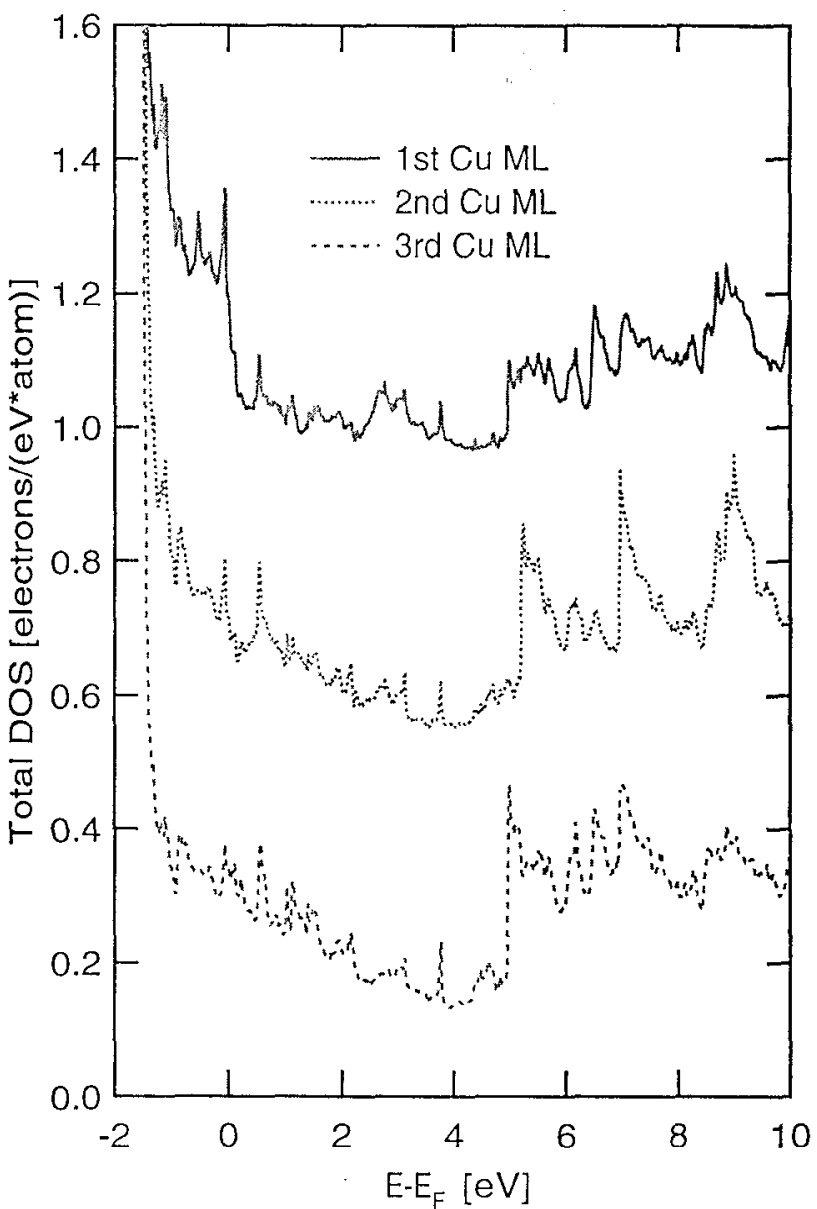

Figure 2. Total DOS

of the individual $\mathrm{Cu}$. monolayers (plots are offset by 0.4 and 0.8 in the vertical axis for clarity.).

In addition to bulk $\mathrm{Cu}$, the total DOS of the multilayer $\mathrm{Cu}_{5} / \mathrm{Cr}_{5}$ was calculated using the FP method, where the $5 \mathrm{Cr}$ monolayers were taken to have the same structure and lattice parameter as bulk $\mathrm{Cr}$ ( $\mathrm{BCC}, \mathrm{a}=2.884 \AA$ ). The $5 \mathrm{Cu}$ monolayers, however, were taken as $\mathrm{BCC}$ with a lattice parameter of $2.829 \AA$, leading to a $2 \%$ lattice mismatch at the interface. The $\mathrm{x}$-ray diffraction data of $\mathrm{Cu}_{5} / \mathrm{Cr}_{5}$ other unpublished results ${ }^{11}$ point to a BCC Cu structure and the specific lattice parameter value.

From the calculations, it is possible to separate the total DOS of individual monolayers in the multilayer in addition to computing the total DOS for the whole multilayer. Shown in Figure 5 are the total DOS for each of the $\mathrm{Cu}$ monolayers in the multilayer - the first $\mathrm{Cu}$ monolayer is the one right next to $\mathrm{Cr}$, and the second $\mathrm{Cu}$ monolayer is the second closest monolayer to the $\mathrm{Cr}$. Integrating the total DOS of the first $\mathrm{Cu}$ monolayer gives 10.85 electrons/atom, which is less than the full 11 electrons/atom expected for bulk $\mathrm{Cu}$. The second $\mathrm{Cu}$ monolayer has 10.89 electrons/atom, which is also less than for bulk $\mathrm{Cu}$, but the third $\mathrm{Cu}$ monolayer has 11 electrons/atom, which is identical to the value for bulk $\mathrm{Cu}$. The same calculations are done for the $\mathrm{Cr}$ monolayers, and the results show that the $\mathrm{Cr}$ monolayer next to $\mathrm{Cu}$ has 6.17 electrons/atom, the next closest has 6.07 electrons/atom, and the third closest has 6.01 electrons/atom, which is identical to the 6 electrons/atom expected for bulk $\mathrm{Cr}$.

The change in charge count relative to the bulk is greatest for the monolayers right at the interface, and the evidence point to charge transfer low from $\mathrm{Cu}$ to $\mathrm{Cr}$ - the first $\mathrm{Cu}$ monolayer loses 0.15 electrons/atom, while the first $\mathrm{Cr}$ monolayer gains 0.17 electrons/atom. The second monolayers also show a net charge transfer - Cu gains 0.11 clectrons/atom, and Cr loses 0.07 electrons/atom.

Figure 2 shows that in the first $\mathrm{Cu}$ monolayer, there is a sharp rise in the DOS at the Fermi energy. This is possibly due to electron states that characterize a bond introduced at the interface between $\mathrm{Cu}$ and $\mathrm{Cr}$, and is where some of the charge transfer occurs. It is reasonable to expect that when there is charge 
transfer between $\mathrm{Cu}$ and $\mathrm{Cr}$ at an interface, the transferred charge gets localized close to the Fermi level since it is at the outermost electron levels where the interaction takes place. The same type of feature in the DOS of the first $\mathrm{Cr}$ monolayer is observed and is even more pronounced. In the region of the Fermi energy there is a sharp peak, which decreases for the second $\mathrm{Cr}$ layer, and finally disappears for the third $\mathrm{Cr}$ layer. The progressive weakening of the peak as the $\mathrm{Cr}$ monolayer gets farther from $\mathrm{Cu}$ indicates that it is associated with the interface. The tigure also shows that in the unoccupied states from the fermi level to about $2 \mathrm{eV}$ above it, the general shape of the DOS remains the same. As previously discussed, the first $\mathrm{Cu}$ ML has a shoulcier right below the Fermi energy. But with a typical average difference (absolute value, point-to-point) of 0.03 , the curves are similar for all three monolayers in that energy region. In another study ${ }^{1}$, we describe and use a technique to calculate the charge transfer from the $\mathrm{x}$-ray absorption. The method uses the fact that the general shape of the DOS from the Fermi energy to about $2 \mathrm{eV}$ above it is similar for the bulk and the monoliayers. There, the calculated charge transfer was 0.026 electrons per interfacial atom.

\section{SUMMARY}

In unannealed samples of $\mathrm{Cu} / \mathrm{Cr}$ of varying period and $\mathrm{Cu}$ composition, the $\mathrm{x}$-ray diffraction scans show one reflection peak, indicating one structure throughout the multilayer. In the $\mathrm{Cr}$ rich samples, the $\mathrm{BCC} \mathrm{Cu}$ has a lattice parameter nearly equal to that of $\mathrm{Cr}$. In the $\mathrm{Cu}_{5} / \mathrm{Cr}_{5}$ sample, annealing to $500 \mathrm{C}$ decomposes the multilayers into bulk-like $\mathrm{Cu}$ and $\mathrm{Cr}$. TEM shows well-defined layering of $\mathrm{Cu}$ and $\mathrm{Cr}$ in a columnar structure in as deposited samples. Analysis of the XAS data show a charge transfer of about 0.03 electrons per interfacial atom, which we believe provides the enhanced bonding at the interface and promotes wetting of $\mathrm{Cr}$ by $\mathrm{Cu}$.

\section{ACKNOWLEDGMENTS}

We would like to acknowledge L. Terminello for arranging the use of beam time at SSRL and ALS, and M. Wall for the TEM analysis. Technical support was provided by Jennifer Alameda and Don Hoffman. This work was performed under the auspices of the U.S. Department of Energy (DOE) by Lawrence Livermore National Laboratory under Contract No. W-7405-Eng-48. TVB was supported by the Division of Materials Science, Office of Basic Energy Science, U.S. DOE. Part of this work was done at the ALS and at SSRL, which are supported by the DOE.

\section{REFERENCES}

$\frac{\text { RE }}{1}$ A. F. Bello, T. Van Buuren, T. W. Barbee, Jr., Conf. MRS Spring Meeting (1998).

${ }^{2}$ A. Guinier, X-Ray Diffraction In Crystals, Imperfect Crystals, and Amorphous Bodies, San Francisco: W. H. Freeman and Co., 1963.

${ }^{3}$ A. P. Payne and B. M. Clemens, J. Mat. Res. 7, 1370-1376 (1992).

${ }^{4}$ M. Grioni, J. F. Van Acker, M. T. Czyzyk, J. C. Fuggle, Phys. Rev. B. 45, 3309-3318 (1992).

${ }^{5}$ J. E. Klepeis, unpublished results (1997).

${ }^{6}$ M. Methfessel, Phys. Rev. B 38, 1537-1540 (1988).

${ }^{7}$ M. Methfessel, C. O. Rodriguez, and O. K. Andersen, Phys. Rev. B 40, 2009-2012 (1989).

${ }^{8}$ R. Hoffmann, Rev. Mod. Phys. 60, 601-628 (1988).

${ }^{9}$ A. K. McMahan, J. E. Klepeis, M. van Schilfgaarde, and M. Methfessel, Phys. Rev. B 50, 10742-10760 (1994).

${ }^{10}$ H. Ebert, J. Stohr, S. S. P. Parkin, M. Samant, and A. Nilsson, Phys. Rev. B. 53, 16067-16073 (1996).

${ }^{11}$ T. W. Barbee, Jr., unpublished results (1997). 